\title{
Cholesterol to HDL-Cholesterol Ratio Measurement
}

National Cancer Institute

\section{Source}

National Cancer Institute. Cholesterol to HDL-Cholesterol Ratio Measurement. NCI

Thesaurus. Code C80171.

The determination of the ratio of total cholesterol compared to high-density lipoprotein type cholesterol present in a sample. The measurement may be expressed as a ratio or percentage. 